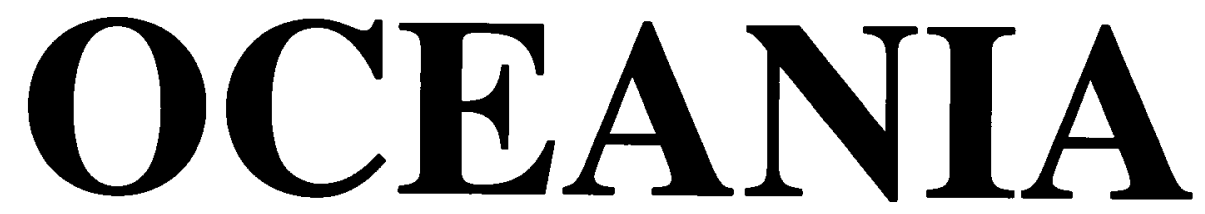

Vol. 77 No. 1

March 2007

\title{
Introduction: HIV and AIDS in Rural Papua New Guinea
}

\author{
Alison Dundon \\ Australian National University \\ Charles Wilde \\ Consultant Anthropologist
}

In late 2004, we were in the peri-urban centre of Balimo in the Western Province of Papua New Guinea where we have been conducting fieldwork for eleven years: Charles initiated a male-only survey on condom use and Alison was interviewing groups of women in the Balimo area about their perceptions and experiences of HIV (Human Immunodeficiency Virus) and AIDS (Acquired Human Immunodeficiency Syndrome). In the context of these surveys and interviews, various issues about HIV and AIDS came to the fore, the details of which form the basis of our papers in this collection. Some comments, however, seemed particularly representative of the dilemmas that many rural Papua New Guineans face as they come to terms with the epidemic of HIV/AIDS: Charles' condom survey, for example, recorded much speculation about the transmission of HIV among men, some respondents listing methods of transmission including 'mosquitos sucking blood and transferring the virus' and 'sharing things, clothes, underpants, cup, spoon, food, smokes, toothbrush', to 'using the same toilet, hugging, kissing [and] sores in the mouth' (Wilde 2005:19). And whilst 112 out of 114 respondents also nominated 'sex' as the primary form of transmission, 23 of these men were convinced that HIV could only be transferred after serial sexual encounters with the same partner rather than during one sexual encounter.

In a women's Christian Fellowship group, many agreed vigorously when one woman argued against the use of condoms as the platform for prevention of the spread of HIV, stating that 'when God created man, he gave them [sexual] organs, and [told them] not to put other things [like condoms] on them'. Another noted that 'our mothers didn't know this sickness [AIDS]. When the sickness came, they introduced the condom: so all the ladies are living in fear of their husbands going away [to work] and coming back wanting to wear condoms'. Condoms, their use and role in preventative programs such as $\mathrm{ABC}$ - practice Abstinence, Be faithful within marriage, and use Condoms - which forms the basis of public health platforms in PNG, are the source of much debate, vitriol and even fear, as we see above. The National AIDS Council Secretariat (NACS), formed by an Act of Parliament in 1997, has established a program for the prevention of the spread of HIV in the country's towns and villages that promotes the use of condoms during sexual liaisons and long-term relationships, but emphasises the former two practices: that is, being faithful to a partner, thereby promoting monogamous sexual relationships, or practising sexual abstinence. The 
NACS' slogan Lukautim yu yet long AIDS, 'protect yourself against AIDS', placed on billboards in the towns and cities, caps, and $t$-shirts as well as posters promoting the use of condoms through sporting heroes, for example, has been one of the major catchcrys of the national campaign. But how do people protect themselves from AIDS when methods of HIV transmission are the source of much speculation and trepidation: is this virus passed through sexual encounters, hugging or kissing, or through sharing utensils or clothing or sitting in the space of another? How can its spread be prevented and what part do condoms, for example, play in this process? In many ways, these papers address the extent to which these national programs have had an impact on people in rural communities, who, in general, travel little to urban centres outside their area or province and whose sources of information about HIV and AIDS include locally organised Church fellowship groups, school presentations, newspapers, radio and workshops organised by health centre staff such as information disseminated on World AIDS Day each year.

This collection of papers focuses on the experiences and understandings of HIV/AIDS in rural PNG, in an important corrective to the focus thus far on urban populations in the dissemination of information about the virus and attendant disease, as well as knowledge of how communities conceptualise HIV/AIDS. The papers offer an insight into some of the ways in which HIV and AIDS have begun to affect the lives and health of rural Papua New Guineans from an anthropological perspective based on ethnographic fieldwork. To date there has been little systematic epidemiological analysis of the epidemic in PNG, particularly in rural areas, so it is difficult to define with any precision the parameters of the problem. And, although there has been recent interest in the exponential growth of diagnosed cases of HIV/AIDS in PNG, there is little written about the nature and extent of the disease in rural communities, although there are some important exceptions (cf. Ballard 2000; Dundon 2005a, 2005b; Eves 2003, Hammar 1996, 1998, 1998a, 1999, 1999a; Koczberski 2000; Lepani 2001; Malau \& Crockett 2000; Wardlow 2002, 2006; Wilde 2005). Other studies have focused on particular aspects of the epidemic in PNG, including AIDS and STDS among 14 to 24 year olds (Jenkins 1997), and sexual and reproductive knowledge throughout PNG (NSRRT \& Jenkins 1994). The four papers by Verena Keck, Katherine Lepani, Charles Wilde and Alison Dundon, examine understandings and experiences of HIV/AIDS from the perspective of, respectively, the Yupno of the Finisterre Range in the Provinces of Morobe and Madang, the Trobriand Islanders of Milne Bay Province, and the Gogodala of Western Province, particularly those in Balimo and surrounding villages.

Each represents a unique and important source of information about the way in which the emerging epidemic is conceptualised in rural communities. Keck, for example, explores young people's knowledge and understandings of HIV/AIDS and prevention strategies among the Yupno, capturing the extent to which rural youth practise pre-marital sex. Dundon demonstrates the centrality of conservative Christianity in Gogodala undertakings to prevent the spread of HIV throughout this community, with an analysis of Prayer Warrior Groups patrolling the streets of Balimo and surrounding villages. In his study of men in Balimo, Wilde shows that men utilise various methods of rationalisation and 'prevention' when sexually active in the community. And Lepani's paper presents an example of the extent to which Trobriand meanings and practices of sexuality depart dramatically from both Christian and public health discourses about 'safe sex', promiscuity and morality. In the Epilogue, Lawrence Hammar provides an insightful and comprehensive discussion of HIV and AIDS and brings together the threads and themes that arise out of these case studies and contextualises them within the larger framework of public health in PNG.

\section{HIV/AIDS IN PNG}

The HIV/AIDS epidemic is relatively new to the Asia Pacific Region and its full impact is yet to be felt, thus a 'window of opportunity' still exists for the region in the implementa- 
tion of strategies to prevent and control the spread of the disease (Linge \& Porter 1997:2). HIV is primarily transmitted sexually, a domain of life often closed to discussion and elucidation, and, in this context, '[e]ducators, health workers and other influential people have to work through a maze of cultural inhibitions'(Linge \& Porter 1997:3). 'With transmission linked to body fluids - to semen and vaginal secretions, blood, and mothers' milk - to sex, reproduction, and death, AIDS in many cultures is freighted with extraordinary symbolic and emotional power' (Schoepf 2001:336). Not only this, but AIDS is often perceived as the result of 'bad' or immoral behaviour, which sets it apart even from other STIs, not only as it almost always results in the death of the patient. At the early stages of a HIV/AIDS epidemic it is difficult for both communities and their political leaders to grasp the implications of it, given, in particular, the extended period of time between infection with HIV and the onset of AIDS (cf.Heald 2003:213; Moodie 1997). Further, HIV seems to affect people between the ages of 15 and 45 , usually the economically productive part of any developing country's population - thus having an enormous potential impact on the economy. Infection rates also seem to multiply rapidly from year to year, and this is coupled with uncertainty as to the patterns of those infected and, thus, future populations and areas of infection. 'In part this is due to the larger tide of humanity travelling in an ever-more complex matrix of movements, thus greatly multiplying and widening opportunities for interpersonal contact' (Linge \& Porter 1997: 7-8).

What came out of our research in Balimo certainly was that questions and speculation about HIV and AIDS dominate discourses about health, illness, morality, sexuality, gender and marriage. Throughout PNG, there are a myriad of differing notions of illness, disease, pathogen, virus, medicine, cure and transmission, with more traditional styles of medicine coming together with Christian healing, apocalyptism and biomedicine (see for example Dundon this collection and Eves 2003): sexuality, STDs and particularly HIV/AIDS, are also understood, imagined and experienced in various ways.' Thus HIV and AIDS may be seen as either separate sicknesses or the same, caused by a pathogen, or the result of sorcery, malicious action or immoral behaviour. So that the perceived transmission of HIV, as we saw in Balimo, can encompass sexual transmission, the mingling of infected blood, and mother to child through breastmilk, birthing or pregnancy, as well as the sharing of utensils, cups and plates, clothing and bedding or a cigarette, or sitting in the vacated place of one with HIV or AIDS (cf. Dundon and Wilde this collection; Eves 2003; Lemeki 2003). Among the Yupno, some young men equate the transmission of HIV with that of tuberculosis, and shun the sharing of foods, plates, cups, lime for chewing betelnut, and cigarettes and even avoid stepping in the footprints of infected persons (Keck, this collection). On Daru, Western Province, it is understood that stepping over the legs of workers from logging camps can transmit the disease, as could contact with a sick person's sores, their toothbrush or even their words (Hammar 1996:484). Thus for them, AIDS is caused by something 'between pathogen (cognised in myriad ways) and bad behaviour (ditto)' (Hammar 1996:486). The symptoms of AIDS range from the presence of 'big sores' on victim's skin and faces, genitalia, buttocks and groins, stained clothes from infected genitalia, to the loss of weight, dryness and darkening of the skin, and loss of hair (see for example Dundon this collection; Eves 2003; Lemeki 2003).

Given these factors, how does a country or community formulate a program for the prevention of the spread of HIV/AIDS? Clement Malau (1999:70) has pointed out that the diversity of Papua New Guinea makes it a difficult country to formulate national programs for HIV/AIDS intervention, with often limited communication between rural and urban populations the result of linguistic and cultural, educational and geographical differences. In combination with a 'shift from a rural subsistence way of life to an urban setting, and the mixing of cultures and subcultures, [this] makes education for behavioural change a very challenging task' (Malau 1999:70). PNG has a well-documented history of high levels of Sexually Transmitted Infections (STIs), since the Chief Medical Officer of Papua noted in 
1914 that the incidence of venereal diseases in Papua was a major problem (Malau 1999:70). Introduced by Europeans over a century ago, Papua New Guineans had little natural immunity to such diseases and lacked a local repertoire to recognise or treat them. As a result, STIs spread rapidly and with great effect throughout the country (Hammar 1998:260). By 1987, PNG was listed as having one of the highest levels of Sexually Transmitted Diseases (STDs) in the world with some 106 infected per 10,000 people (Malau 1999:70).

The connection between STDs or STIs and HIV/AIDS is well documented: the presence of STIs significantly increases the risk of contracting HIV during sexual contact. The treatment of STIs and the maintenance of sexual health is paramount to the prevention of the spread of HIV. Recent figures indicate that PNG has the highest STI rates in the Pacific, coming in fourth behind Thailand, Cambodia and Myanmar in the Asia Pacific region (The National, 4 April 2006). In 1987, the first case of HIV infection in PNG was recorded. A Safe Blood Supply Policy was implemented the following year, and infection rates rose slowly for the next six to seven years. By 1994, confirmed cases had risen by $72 \%$ on the previous year, and, by 1995, 80\% over 1994 (Jenkins 1997:2). Such numbers reflect only a very small number of those with HIV in PNG, however, as testing is still sporadic and surveillance incomplete (Jenkins 1997:2). PNG's AIDS epidemic has become generalized since then, only the fourth country in the Asia-Pacific region where this has happened. Official cases of HIV/AIDS reached 4792 by 2001 , and a culmative total of 9851 by the end of June 2004, but unofficial estimates of the number of people in PNG with HIV and/or AIDS in 2000 were closer to between 15000 and 22000 and exponentially more in 2004 (Moiya 2004; NACS and Department of Health DOH 2004). Dr Joachim Pantumari, senior medical advisor to NACS, has recently stated that 11800 Papua New Guineans have confirmed cases of HIV/AIDs, with another estimated 70000 as yet unaware of their sero-status (The National 4 April 2006), while NACS Quarterly Report for December 2005 reports a figure of 14164 as the cumulative total of notified HIV cases for the end of 2005 (NACS 2005). Teenagers already constitute more than $10 \%$ of all reported infections of HIV in PNG (Jenkins 1997:1) with $6 \%$ male and $16 \%$ female in the $15-19$ age group, $15 \%$ male and $55 \%$ female in 20-24 year age group, 24\% of males and 52\% of females with HIV in the 25-34 year age group (NACS 2005). AIDS is the leading cause of death in Port Moresby General Hospital Medical Ward (Malau 1999:70). The National Capital District (NCD) reported $61 \%$ of HIV cases in the country, with Western Highlands Province following with $17 \%$ of recorded HIV cases (NACS and DOH 2004). The numbers of those infected with HIV are projected to increase by up to $30 \%$ per year, with primary infections affecting the 15-34 age group, and it is projected by WHO that in fifteen to twenty years, there will up to 40 million people infected with HIV/AIDS in the Asia/ Pacific region (Dupont 2001:5).

\section{RISK, GENDER AND SEXUAL HEALTH}

Sexual behaviours in PNG are complex, with practices in rural and, increasingly, urban contexts taking very different forms (see Jenkins 1997). This, Malau (1999:70) suggests, renders 'sexual networking more complex than in the past, particularly with permissive cultural sexual encounters in traditional settings in some societies in the country'. This has farreaching implications for the impending HIV/AIDS epidemic. Jenkins and Passey (1998:234) note that attitudes to sexuality range from 'highly permissive' to 'prudish and repressive'. They suggest that PNG exhibits several prominent cultural and sexual factors associated with high risk sexual practice: these include generally low levels of knowledge about sexual function or anatomy, reproduction and STDS including HIV/AIDS and concomitant low treatment levels for STDS, particularly for women; a widespread acceptance of multiple sexual partners for men; an increasingly widespread commercialisation of sex coupled with high levels of forced sex and rape, both inside and outside of marriage, and 
group sex (Jenkins \& Passey 1998:235). Combined with the increased use of alcohol, marijuana, the desire and need for cash, accessibility of pornography and dances and clubs that bring together all of the above elements, these factors can and do 'fuel high-risk sexual behaviour' (Jenkins and Passey 1998:235). Hammar (1992:42), for example, argues that, on Daru, sexual patterns and behaviours are increasingly affected by 'drinking, adultery, and associated male violence, high unemployment, male labour migration, and environmental destruction, changing kinship expectations, inflated brideprices, and an increase in zelasi (jealousy) and mido (sorcery) accusations'.

Jenkins (1997) reports that knowledge about sexuality, sex and reproduction is generally low, particularly amongst young people. Throughout PNG, the average age for first sexual encounters is between 15-16 years, for both women and men, which means that few 'enter a sexual relationship with any knowledge of contraception or STDS' (Jenkins 1997:13). She argues that, although there are a few exceptions, most schools and Churches do not carry out educational programs that adequately address issues of sex and reproduction, and parents, in general, tend to withhold knowledge about such issues from their children. As a result, most young people in PNG learn about sex and reproduction, and diseases like STIS and HIV, from older male or female friends or relatives (Jenkins 1997:15). Lemeki (2003:49) notes, that in the EHP, young women or girls learn about sex, their bodies, reproduction and STDS from older female relatives, while young men's sources of sexual information tend to be media-based, including videos and magazines, as well as older siblings and male friends. 'The formal education system has not been a major source of sex and reproductive information as reported by informants' (Lemeki 2003:48). Usually only those who complete Grade 10 or higher exhibit a conception of biology and anatomy taught in PNG schools. These young women and men are more likely to use this information to make choices about contraception for the prevention of STDS, including HIV, and unwanted pregnancies.

In many instances, health services may not make contraception available to a wide range of people, particularly young people (Jenkins 1997:14). Wilde (2005) notes that, in Balimo, contraception is strictly controlled by the Sisters at the Health Centre, whose policy is to restrict the distribution of contraception to married couples attending the Family Planning Clinic. Thus, those men and women engaging in sexual encounters outside marriage are denied access to contraceptive devices, particularly condoms, which are not freely available anywhere else in the District. Keck also documents that Yupno youths, male and female, find it difficult to access condoms from the health centres at Teptep and Kangulut. Citing both kastom and Christianity, health workers routinely turn away unmarried persons. Yet Lemeki (2003), in a study of young people between 15 and 25 years of age in Eastern Highlands Province (EHP), records that multiple sexual partners were relatively common amongst informants, including serial monogamous relationships or marriages. Women reported that their husbands regularly engaged in extramarital sex, much of which was transactional (Lemeki 2003:74). Extramarital affairs were common in both rural and urban contexts in EHP, for which several reasons were proffered but the most common was 'sex for cash' (Lemeki 2003:75).

The movement of men throughout the country in the pursuit of paid employment and other opportunities, resulting, amongst other things, in the use of new sexual techniques and the tendency to participate with many partners in sexual relationships, often simultaneously, is acknowledged as a primary force in the transmission of HIV. Mobility and out-migration greatly increases the risk of HIV infection, as they are often undertaken by sexually active young men who are more likely to engage in 'risky sex' without the social constraints of village life (Koczberski 2000:52). Wilde (2005) has noted a correlation between young men who spend periods of time, anywhere from a month to several years, outside their area in logging camps or urban environments in PNG, and increases in 'risk behaviour', including multiple sexual partners, unprotected sexual encounters and sex for cash. 
'Gender based violence' is also common in PNG although rarely a serious topic of conversation, notes Malau (1999:70), yet it is having a significant impact on the way the 'epidemic will continue to evolve in Papua New Guinea'. Jenkins (1997:19) suggests that rape, either singular or group rape, is 'disturbingly common' and that there is some evidence that group rapes, for example, present a great danger as they result in the spread of HIV and other STDS in fast succession, not just to those involved, but to their extended range of present and future sexual partners and children (Jenkins 1997:20). Lemeki (2003:80) reports that, amongst young people in EHP, 'forced sex or rape was reported in all areas sampled in both studies' and was a major part of recorded interviews throughout the study, young men particularly speaking openly about it. Some young men, she writes, saw rape as an opportunity for sex, one not necessarily afforded them in other circumstances (Lemeki 2003:80). 'Since they could not afford sex because of the lack of cash, forced sex was an option for getting free sex. Women were victims who were often seen to be at fault, for being at the wrong place at the wrong time and engaging in provocative behaviour' (Lemeki 2003:80). Many rapes occurred during social dances or video nights.

Women play a key role in the health of their communities, as many of them are primary carers and providers for their families (cf. Bloom et al. 2001). But women are also often those most vulnerable in these societies, as they may not have access to vital educational and health care services, or may be victims of sexual and/or domestic violence. ${ }^{2}$ In PNG in $2006,46 \%$ of confirmed cases are female, $48 \%$ male and $6 \%$ not recorded (The National 4 April 2006). Thus, many of the cases of HIV/AIDS in PNG involve women and children, as the primary forms of transmission are heterosexual intercourse and perinatal transmission. In PNG, like much of the non-industrialised world, then, HIV/AIDS is a disease that greatly affects women and children. The National Sex and Reproductive Research Team (NSRRT) in conjunction with Carol Jenkins (1994:128) found that STDs amongst rural women were common, upwards of $30 \%$ of women, many of who contracted STDs from their spouses. At least $30 \%$ of these women never sought medical help and a further $20 \%$ failed to complete their treatment. Most stated that they felt too embarrassed to seek help, others were prevented from attending by their spouses, and others were offended by the attitude of health workers. Only $3 \%$ of the rural women who participated in the study had any idea that condoms could be used to prevent infection with STDs and HIV during sexual intercourse. Women are also more likely to be rejected by their families if they fall ill. In global terms, women's vulnerability to HIV/AIDS also translates to reduced life expectancy in comparison to men with HIV (WHO 1998:25). Thus NSRRT and Jenkins (1994:141) concluded that

[g]ender issues loomed large in the results of this study. The rights of women to redress for rape, in and out of marriage, to better, more specialised health services, to income-generating options, and to greater access to information and the means by which to avoid unwanted pregnancies and STDS, including HIV infection, cannot be ignored much longer in Papua New Guinea.

\section{RURAL UNDERSTANDING OF THE HIV EPIDEMIC}

These issues and factors come together in PNG to create a situation in which HIV and AIDS has become an undeniable yet, in some places, still invisible presence in rural communities. Most, however, have heard about HIV/AIDS, and people are increasingly diagnosed with either HIV and/or AIDS in the Aid posts, health centres and hospitals of the country. It represents a growing concern for the national and regional governments as well as local communities, and poses some important questions for public health and governmentality in PNG. As Parker (2001:169-170) suggests, 
different societies organize sexual (as well as other forms of) inequality in specific ways, social and cultural rules and regulations place specific limitations on the potential for negotiation in sexual interactions. These rules and regulations, in turn, condition the possibilities for the occurrence of sexual violence, for patterns of contraceptive use, for sexual negotiation, for HIV/AIDS risk reduction strategies, and so on.

Although the authors of these papers focus on differing aspects of the impending epidemic in these communities, certain common issues arise out of this collection. The first of these is the centrality of Christian concepts, practices and institutions in understandings of the disease, its transmission, symptoms and those affected by it, as well as sexuality, gender, marriage and family planning. From prayer groups fighting the spread of HIV with the clarity and powers bestowed by contact with the Holy Spirit, to representations of AIDS as God's punishment on those who contravene both customary and Christian tenets, Christianity is central to the experience of HIV/AIDS in rural PNG. Dundon's paper, for example, draws on a local evangelical Christian dialogue among the Gogodala that accentuates the role of the breakdown of sexual inhibitions and prescriptions, and other Christian principles and practices in the influx of HIV into the area. She follows a group of Christian women, referred to as 'Warrior women', who patrol the villages of the district in a bid to make public illicit sexual liaisons in an attempt to tackle the silent and invisible spread of the virus. Touched by the Holy Spirit and able to 'see' those who transgress sexual and social prescriptions, these women, however, also have the potential to become like those they seek to shame through a form of madness that causes them to challenge social and sexual constraints. Keck explores the extent to which young people in the Finisterre Range have access to information about HIV/AIDS, and how this shapes their understandings of the illness. She argues that their level of knowledge about HIV/AIDS and the kinds of preventative measures that they adopt (if any) must be contextualised within a dialogue that brings together kastom and a form of Lutheran Christianity. In this context, HIV/AIDS is understood as God's punishment to those who 'roam around', engaging in sexual relationships not sanctioned by the Church or contemporary notions of Yupno kastom.

Wilde examines the responses of men to a survey on condom use and sexual behaviour in light of the recent influx of HIV/AIDS into Balimo. He suggests that although the respondents showed a relatively high degree of extramarital or premarital sexual experience and little or intermittent use of condoms, men seek to represent their behaviour in ways that minimise the perception that these practices place them at any greater risk than others in the community of contracting and spreading the HIV virus. They believe that by demonstrating their worth through the principles and practices of dala ela gi, the 'male way of life', of which an integral part is an allegiance to Christianity, they prove to the wider community that their lifestyle does not pose a threat to either themselves or others. In her paper, Lepani analyses the way in which Trobriand Islanders, unsettled by the contradiction between public health programs about HIV and AIDS, and its conflation with 'sexual deviance' and excess and Christian morality, and their own understandings of the relationship between sexuality and disease, speculate that HIV/AIDS is comparable to a local illness called sovasova. Arising in those who conduct sexual relationships with members of their own clan, the symptoms of sovasova are similar to that of AIDS, although the former is both easily prevented and treated. Lepani notes that, despite some dispute and ambiguity about the comparison between AIDS and sovasova, it nonetheless has serious implications for the community's mediation and interpretation of knowledge about HIV/AIDS.

Secondly, in many rural communities AIDS is conceived as a disease of others, of outsiders - whether Europeans, other Papua New Guineans, or those in paid employment in cities and towns. Lepani (2001:92; and this collection) reports that Trobriand Islanders see HIV as the result of foreign and high risk behaviour and is associated with those who come 
from the outside - 'boatcrews, tourists, Papua New Guineans from other areas, dimdims (white people or foreigners)'. Trobriand women, she suggests, feel safe in their normative context and within the parameters of their sexual behaviour. So that, for them, 'safe sex' is equated with sexual activities that are culturally valued as natural and safe (Lepani 2001:93). Dundon (this collection; 2005b) argues that Gogodala women believe that AIDS derives from outsiders and that prevention rides on the physical and metaphorical separation of Gogodala from others, whether Papua New Guinean, European or Gogodala workers returning from other places. In this context, this has recently served to revitalise a conservative Christian discourse on marriage and sexuality. While Wilde notes the ways in which Gogodala men are utilising this discourse, that AIDS is the disease of outsiders, to convince others in the community that their movements between nearby logging camps and home villages represent movement within the known local environment. Thus, they argue, their behaviour does not place them or others with whom they engage in any more danger of contracting HIV than those who live in the village. Keck similarly shows how Yupno youths believe that HIV/AIDS derives from other, primarily urban contexts, and that it is those who live in or visit town, particularly young men who 'roam around', who represent the greatest risk of contracting and spreading the virus.

Thirdly, then, these papers bring to the fore the extent to which categories of behaviour and persons, central to national and international programs of prevention and represented in terms like 'risk group', 'risk behaviour' and 'safe sex' for example, are increasingly problematic in rural contexts. The ways in which HIV/AIDS is conceived within biomedicine promulgates a notion of disease, particularly in terms of HIV/AIDS, as the choice of the individual - to either 'protect' themselves through the practice of safe sex and the use of condoms for example, or 'allow' themselves to become infected through participation in certain sexual and/or other risky activities. Hammar (1999:116) argues that global health education about HIV/AIDS stresses a monocausal agent of the disease - HIV - and promotes 'individual solutions to disease prevention, though these just as obviously spring from structural forces and problems'. Such approaches focus on individual behavioural, motivational and psychological change as the basis of prevention programs. Lepani (2001:2) has noted that HIV prevention strategies tend to rely on the education of target or risk groups in order to achieve change, and are "largely based on the agency of the individual as the sole decision-maker'. Are there, however, the same individual and individuated bodies and persons in PNG, and thus ability to make choices about sexuality and other practices, that this model assumes (cf. Schoepf 2001)? Moreover, what could be construed in national programs on HIV prevention as 'promiscuous sex' and 'risk behaviour' is in the Trobriands, for example, not only common practice but vital to the development of interclan relations and the perpetuation of the clan through the maintenance of 'relations of difference'. Increasingly among the Gogodala, 'safe sex' is embodied in various risk reduction strategies adopted by young mobile and sexually active men in their quest to demonstrate to the community the viability and benign nature of their sexual relationships and movements between town, logging camps and village. The category 'risk group' is thrown into confusion by Christian women touched by the Holy Spirit, who bring 'out to the people' the activities of those seen to endanger the wider community through illicit sexual contacts, becoming the victims of their own campaigns. The destabilisation of categories central to biomedical programs and dialogues about HIV/AIDS in PNG has potentially wide-ranging implications for programs of prevention in rural communities: for many do not feel themselves, or those around them, to be the target of these programs, for they do not participate in 'risk behaviour' and are not part of the 'risk groups' spoken about in workshops or at the health centres. Thus the messages do not apply to them, nor are they, in many cases, heard.

Finally, these papers pinpoint the significance of health workers in rural PNG and the ways in which these people shape the dissemination of knowledge and material (including condoms) about HIV/AIDS as well as its experience. Keck draws attention to the role that 
health workers play in informing young people about HIV and AIDS, as well as their access to (or lack thereof) prophylactics like condoms. She writes that young men she spoke to noted that health workers only distributed condoms to married men: teenagers were refused condoms and instructed instead to refrain from 'roaming around'. Wilde and Dundon similarly note the prescriptive measures taken by the Balimo Health Centre, for example, in the distribution of condoms. They show that the use of condoms in Balimo is firmly policed by the nursing sisters at the Family Planning Clinic, who only distribute them to men in the presence of their wives. Wilde writes that on World AIDS Day in 2003, female health workers spent much of the day debating their role as both Christians and health professionals in the dissemination of information about HIV and AIDS and the use of condoms. Hammar also draws attention to the crisis that many health workers throughout PNG face when talking about HIV, sex, condoms and preventative programs based on ABC. Many health workers struggle with moral dilemmas that arise in their work in both religious and secular health centres, hospitals and aid posts throughout PNG, which often arise out of conflicting doctrines and practices in health centres and churches, as well as wider community, family and kin groups. Facilities and programs face many of the same problems, beset by "personal as well as institutional, logistic in addition to philosophical' contradictions and conflicts.

Since Herdt (1987) first called anthropologists to play a prominent role in conceptualisations of the virus and resulting disease, it has been noted that understandings of the ways in which people experience and understand HIV and AIDS are vital to the prevention and management of the epidemic. ${ }^{3}$ In their papers, the contributors suggest that the development of policies and programs for the prevention of the spread of HIV must be based on an understanding of the extent to which the rural context shapes the response to the disease. They suggest various strategies from the utilisation of sporting activities like rugby league for engaging young men about sexuality and condom use; the use of campaigns about the ways in which sexuality occurs in rural areas and with which rural people can identify; to addressing the issue of sexual education in general but particularly for young people, as well as addressing other forms of inequalities of education and accessibility in rural areas. As Hammar argues, however, there will need to be an 'all-out, non-compromising, evidence-based approach' to the spread of HIV, one that embraces the realities of transmission routes and risks of HIV throughout the country: and that 'resigned adaptation' will have to give way to attempts to challenge and transform factors within PNG that make it susceptible to the force of the epidemic.

\section{NOTES}

1. Hammar (1998:273), for example, argues that those on the island of Daru, Western Province, have 'authoritatively blended both traditional' and 'modern' models of sickness based on knowledge of sorcery, contagion, germ theory, and sexual transmission'.

2. AIDS is increasingly a 'female affair' (WHO 1998:28). In recent years, heterosexual transmission has become the dominant form of transmission of the virus, and in Africa, there are already 6 women to every 5 men infected with HIV/AIDS. Women now account for 42\% of people with HIV (WHO 1998:23) and there has been much interest in the role HIV plays in the lives of African women and children (see for example Bassett \& Mhloyi 1994; Krieger \& Margo 1994; Lyons 1995; Schoepf 1992).

3. Anthropology and anthropologists can play a major role in understandings of the disease and its effects on diverse populations as well as the implementation of programs of intervention, treatment and care (see for example Ellison et al. 2003; Farmer 1992; Heald 2003; Parker 2001; Schoepf 2001). Anthropology, writes Farmer (1992:262), "has much to offer those who seek a full and rich understanding of AIDS which is of no small importance to efforts to halt the spread of HIV'. Similarly, Schoepf (2001:336) notes that disease epidemics are 'social processes' and the spread of 'infectious agents is shaped by political economy, social relations and culture'.

\section{REFERENCES}

BALLARD. J. 2000. Introduction: HIV and development. Development Bulletin 52: 4-5.

BASSETT. M. T. \& M. MHLOYI. 1994. Women and AIDS in Zimbabwe: The Making of an Epidemic. In Krieger 
\& G. Margo eds. AIDS: The politics of Survival, pp. 125-139. New York: Baywood Publishing Company.

BLOOM. D. RIVER PATH ASSOCIATES \& J. SEVILLA. 2001. Health, Wealth, Aids and Poverty. In AusAID. HIV/AIDS and development in Asia and the Pacific: A lengthening shadow, Canberra: AusAID.

DUNDON. A. 2005a. Sickness without medicine: HIV/AIDS and changing perceptions of illness and healing in Western Province, Papua New Guinea. Paper presented at Australian Anthropological Society Conference, Adelaide.

2005b. Building a wall around Christian country in Western Province, Papua New Guinea. Paper presented at Australian Anthropological Society Conference, Adelaide.

DUPONT. A. 2001. HIVIAIDS: A major international security issue. HIV/AIDS and Development in Asia and the Pacific, Canberta: AusAID.

ELLISON. G, M. PARKER \& C. CAMPBELL 2003. Introduction. Learning from HIV and AIDS: from multidisciplinary to interdisciplinarity. In G. Ellison, M. Parker \& C. Campbell. (Eds). Learning from HIV and AIDS, pp. 1-31. Cambridge: Cambridge University Press.

EVES. R. 2003. AIDS and apocalypticism: interpretations of the epidemic from Papua New Guinea. Culture, Health \& Sexuality 5 (3): 249-264.

FARMER. P. 1992. AIDS and Accusation: Haiti and the Geography of Blame, Berkeley and Los Angeles: University of California Press.

HAMMAR. L. 1992. Sexual transactions on Daru: with some observations on the ethnographic enterprise. Research in Melanesia 16: 21-54.

1996. Sex and Political economy in the South Fly: Daru Island, Western Province, Papua New Guinea. PH.D dissertation, City University of New York.

1998. AIDS, STDs, and sex work in Papua New Guinea. In L. Zimmer-Tamakoshi. (ed.) Modern Papua New Guinea, pp. 257-296. Kirksville, MO: Thomas Jefferson University Press.

1998a. Sex industries and sexual networking in Papua New Guinea: public health risks and implications. Pacific Health Dialogue 5(1): 47-53.

1999. Staking out the middle range between the macro- and micro-disease in the social structure. Pacific Health Dialogue 6(1): 112-121.

1999a. Caught between structure and agency: the gender of violence and prostitution in Papua New Guinea. Transforming Anthropology 8(1\&2): 77-96.

HEALD. S. 2003. An absence of anthropology: critical reflections on anthropology and AIDS policy and practice in Africa. In G. Ellison, M. Parker \& C. Campbell. (Eds). Learning from HIV and AIDS, pp. 210-237. Cambridge: Cambridge University Press.

HERDT. G. 1987. AIDS and anthropology. Anthropology Today 3: 1-3.

JENKINS. C. 1997. Youth in Danger: AIDS and STDS among young people in Papua New Guinea, Port Moresby, Papua New Guinea: UNFPA.

JENKINS. C. \& M. PASSEY. 1998. Papua New Guinea. In T. Brown et al. (eds). Sexually Transmitted Diseases in Asia and the Pacific, pp. 230-254. Armidale: Venerology Publishing Inc.

THE NATIONAL SEX AND REPRODUCTION RESEARCH TEAM \& C. JENKINS. 1994. National Study of Sexual and Reproductive Knowledge and Behaviour in Papua New Guinea, Goroka: Papua New Guinea Institute of Medical Research, Monograph No. 10.

KOCZBERSKI. G. 2000. The sociocultural and economic context of HIV/AIDS in Papua New Guinea. Development Bulletin 52: 61-3.

KRIEGER. N. \& G. MARGO. 1994. Introduction: Women and AIDS. In N. Krieger \& G. Margo (eds). AIDS: The politics of Survival, pp. 107-110. New York: Baywood Publishing Company.

LEMEKI. M. 2003. Sexually transmitted diseases and HIV/AIDS knowledge and sexual behaviour among Eastern Highlands youth, Papua New Guinea. M.A. thesis, Canberra: Australian National University.

LEPANI. K. 2001. Negotiating 'Open space': The importance of cultural context in HIV/AIDS communication models. A qualitative study of gender, sexuality, and reproduction in the Trobriand Islands of Papua New Guinea. M.P.H thesis, University of Queensland.

LINGE. G. \& D. PORTER. 1997. HIV/AIDS and development. In G. Linge \& D. Porter (eds). No Place for Borders: The HIVIAIDS epidemic and development in Asia and the Pacific. Pp. 1-23. Australia: Allen and Unwin.

LYONS. M. 1995. Women's Destiny and AIDS in Uganda. In C. Hannaway, V. A. Harden \& J. Parascandola (eds). AIDS and the Public Debate: Historical and Contemporary Perspectives, pp. 187-201. Netherlands: IOS Press.

MALAU. C. 1999. The evolving AIDS epidemic: Challenges and responses in Papua New Guinea. Development Bulletin 50: 70-71.

MALAU. C \& S. CROCKETT. 2000. HIV and development the Papua New Guinea way. Development Bulletin 52: $58-60$

MOIYA. N. 2004. PNG Response to the HIV/AIDS Epidemic. Paper presented at HIV/AIDS in PNG: Priorities for Policy and Social Research Workshop, ANU, Canberra.

MOODIE. R. 1997. The situation now and possible futures. In G. Linge \& D. Porter (eds). No Place for Borders: The HIV/AIDS epidemic and development in Asia and the Pacific. pp. 24-39. Australia: Allen and Unwin.

NATIONAL AIDS COUNCIL SECRETARIAT. 2005. Quarterly Report, December, Port Moresby.

NATIONAL AIDS COUNCIL SECRETARIAT \& DEPARTMENT OF HEALTH. 2004. Annual report, Port Moresby. 
PARKER. R. 2001. Sexuality, Culture, and Power in HIV/AIDS research. Annual Review of Anthropology 30: 163179.

SCHOEPF. B.G. 1992. Women at risk: Case studies from Zaire. In G. Herdt \& S. Lindenbaum (eds). The Time of AIDS: Social Analysis, Theory and Method, pp. 259-286. Newbury Park, CA: Sage.

2001. International AIDS research in Anthropology. Annual Review of Anthropology 30: 335-361.

WARDLOW. H. 2002. Passenger-women: changing gender relations in the Tari Basin. Papua New Guinea Medical Journal 45(1-2): 142-146.

2006. Wayward Women: Sexuality and Agency in a New Guinea Society, California: University of California Press.

WILDE. C. 2005. Condom Use in Rural PNG: Awareness, Access and Acceptance among Men in the Middle-Fly of Western Province. Port Moresby: National AIDS Council.

WORLD HEALTH ORGANISATION. 1998. Gender and Health: Technical Paper, Switzerland. 